\title{
Stereotactic body radiation therapy for pulmonary large cell neuroendocrine carcinoma: a case report
}

This article was published in the following Dove Medical Press journal:

OncoTargets and Therapy

In Young Jo

Seung-Gu Yeo

Department of Radiation Oncology, Soonchunhyang University College of Medicine, Soonchunhyang University

Hospital, Cheonan, Republic of Korea

\begin{abstract}
The incidence of large cell neuroendocrine carcinoma (LCNEC) of the lung is rare, and the treatment methods and prognosis for such patients are still subjects of debate. We report a case of a 78-year-old male LCNEC patient for whom stereotactic body radiation therapy was performed. A four-dimensional computed tomography scan was used for simulation, and radiotherapy was planned using the volumetrically modulated arc technique. A total of $55 \mathrm{~Gy}$ was delivered in five daily fractions. The treatment was safely completed, and the patient did not report any discomfort. The only side-effect was an intermittent cough. Currently, the patient has received 18 months of outpatient follow-up care with no evidence of disease. In conclusion, stereotactic body radiation therapy can be a valuable treatment option for early stage LCNEC. Keywords: lung, large cell, neuroendocrine carcinoma, stereotactic ablative radiotherapy, radiation therapy
\end{abstract}

\section{Introduction}

Large cell neuroendocrine carcinoma (LCNEC) of the lung is a very rare lung cancer, with a rate of $\sim 1 \%$ of all lung cancer patients. ${ }^{1,2}$ Although the histological features of LCNEC are similar to those of small cell lung cancer (SCLC), the biological features of LCNEC are more similar to those of non-small-cell lung cancer (NSCLC). ${ }^{3}$ There are no established treatment guidelines for LCNEC. ${ }^{3}$ However, if possible, surgery for early stage LCNEC is recommended because it is not only possible to make a final diagnosis but it can also be an important basis for planning the patient's treatment after surgery. ${ }^{4}$ If surgery cannot be performed, stereotactic body radiation therapy (SBRT) may serve as a useful alternative treatment for early stage NSCLC..$^{5-7}$ However, SBRT is not yet established as an appropriate treatment for early stage SCLC ${ }^{8}$ Here, we report the case of a patient with stage IA LCNEC for whom SBRT was performed after refusal of surgical resection. The patient is currently under outpatient follow-up care with no evidence of disease 18 months after SBRT completion.

\section{Case report}

The patient was a 78-year-old man with a smoking history of 50 pack-years. He had a 25-year history of type II diabetes mellitus and benign prostate hypertrophy, and there was a history of several hospitalizations due to hypoglycemic shock from unregulated type II diabetes mellitus and pneumonia. At the age of 12, he lost his right arm at the time of the Korean War. The patient gave written informed consent for publication of his case details and images. The study was approved by the Institutional Review Board of Soonchunhyang University Cheonan Hospital (approval no SCHCA 2018-05-052).
Correspondence: Seung-Gu Yeo Department of Radiation Oncology, Soonchunhyang University College of Medicine, Soonchunhyang University Hospital, 3I, Sooncheonhyang 6-gil, Cheonan 3II5I, Republic of Korea Tel +82 4I 5703557

Fax +82 4I 5923809

Email md6630@schmc.ac.kr 
The patient underwent chest X-ray in March 2017 for a routine medical examination. A consolidative ground glass opacity was observed in the left upper lobe. Chest computed tomography (CT) with contrast enhancement revealed an $\sim 2.6-\mathrm{cm}$-sized lung mass without any lymph node enlargement (Figure 1). Percutaneous needle biopsy confirmed that the mass was an LCNEC. Immunohistochemical analysis showed positivity for CK7 and CD56 and focal positivity for chromogranin A, TTF-1, and P63. Synaptophysin was weakly positive, and napsin-A, P40, and ALK were negative. EGFR mutation in exons 18, 19, 20, and 21 was not found, and $A L K$ gene translocation was negative.

Bronchoscopy with endobronchial ultrasound biopsy was performed to determine the mediastinal stage. The $4 \mathrm{R}$ and 7 station lymph nodes were negative. ${ }^{18} \mathrm{~F}$-fluorodeoxyglucose positron emission tomography-CT showed no abnormal metabolic activity except for left upper lobe lung cancer (maximum standardized uptake value 12.1) and an incidental parotid Warthin tumor (Figure 2). Lung perfusion scan showed only a few multifocal perfusion defects due to underlying emphysema in both lung fields and no segmental perfusion defect. Finally, the patient was diagnosed with LCNEC T1cN0M0, stage IA, according to the criteria of the American Joint Committee on Cancer, eighth edition.

Surgery was recommended to the patient, but he was reluctant to undergo surgery. He was also consulted about radiation therapy (RT). SBRT was considered because the tumor was $<5 \mathrm{~cm}$ in diameter, located peripherally in the lung, and the RT target did not include the regional lymph nodes. Finally, the patient decided to undergo SBRT.

The patient underwent respiration-correlated 4D-CT (Brilliance CT Big Bore; Philips Medical Systems, Cleveland, $\mathrm{OH}, \mathrm{USA}$ ) for simulation. The gross tumor volume was contoured in the mediastinal window setting, and the clinical target volume was expanded by $0.5 \mathrm{~cm}$ around the gross tumor volume. The internal target volume was the sum of the clinical target volumes of all ten respiratory phases. The planning target volume was created by adding $0.5-\mathrm{cm}$ isotropic set-up margins all around the internal target volume. The planning target volume was $58.5 \mathrm{~mL}$. The treatment plan was created using the volumetrically modulated arc technique
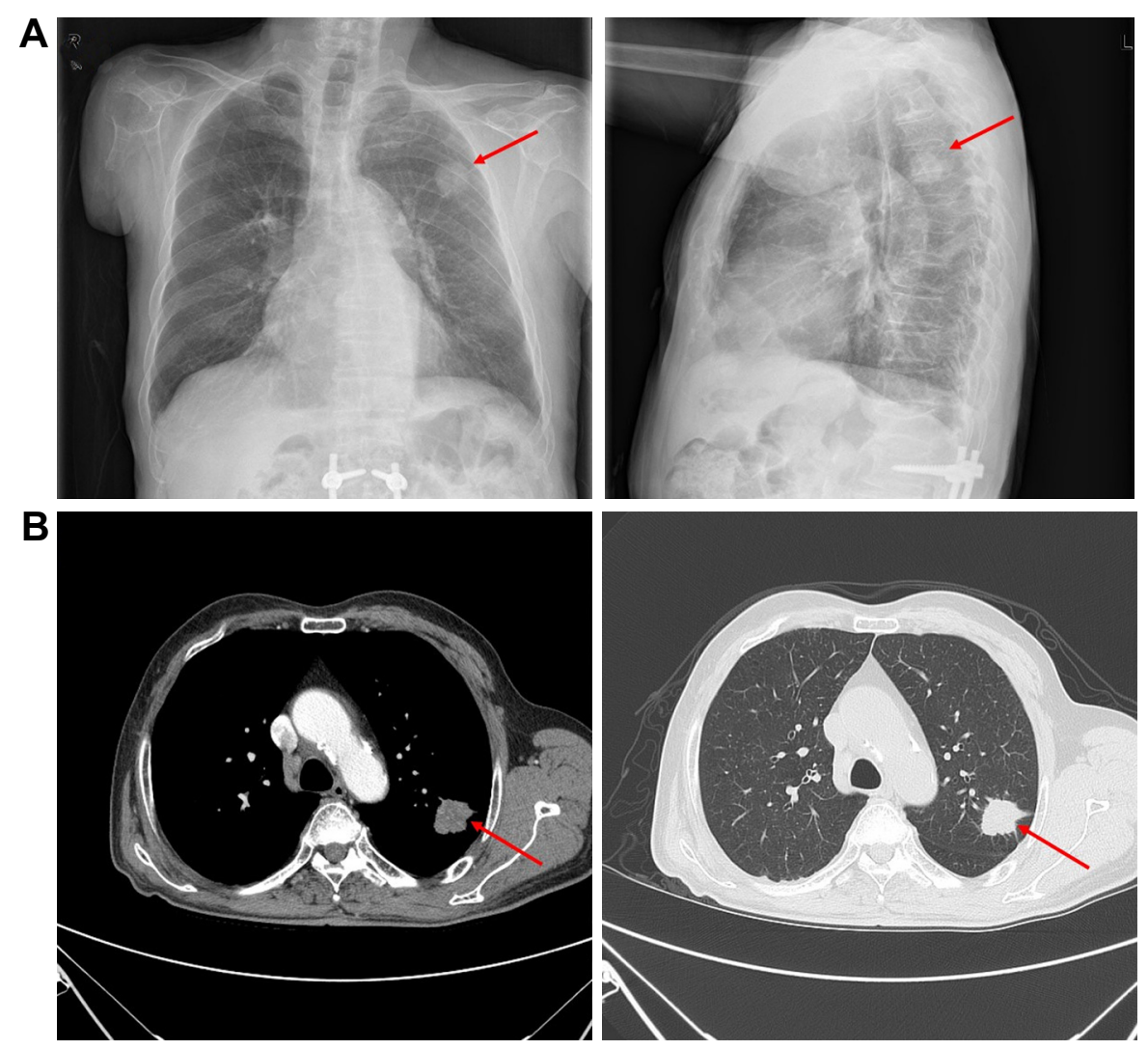

Figure I Pretreatment chest images.

Note: A 2.6-cm-sized left upper lobe mass (red arrows) was observed in chest $X$-ray (A) and CT (B).

Abbreviation: CT, computed tomography. 

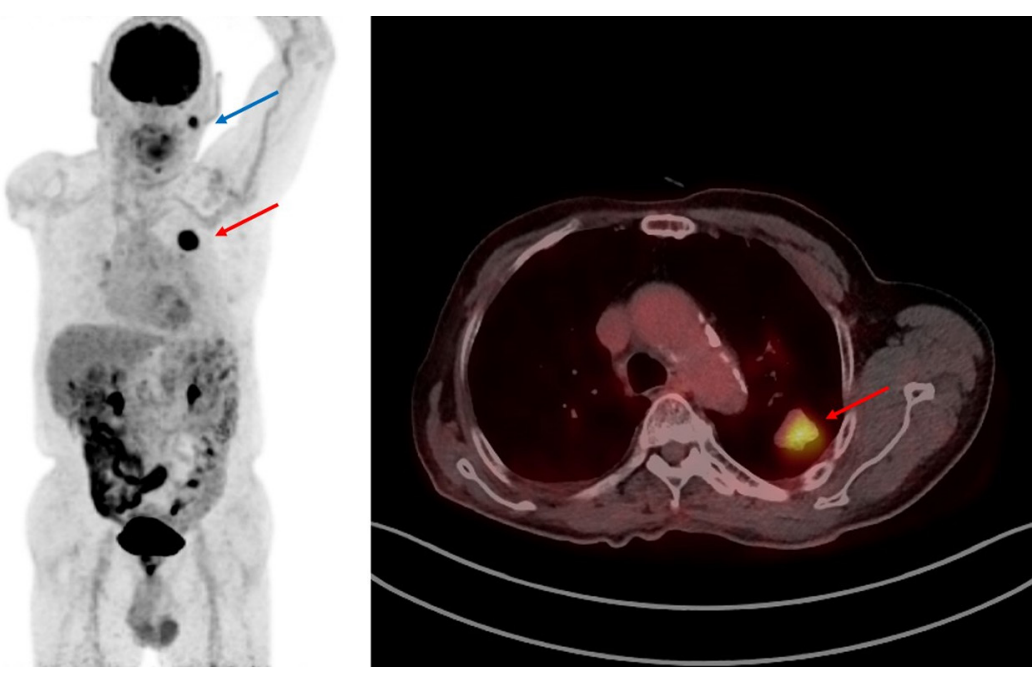

Figure 2 Pretreatment ${ }^{18} \mathrm{~F}$-fluorodeoxyglucose positron emission tomography/CT images.

Note: There was no lesion with abnormal metabolic activity except for LCNEC (red arrows) in the left upper lobe and a Warthin tumor in the left parotid gland (blue arrow). Abbreviations: CT, computed tomography; LCNEC, large cell neuroendocrine carcinoma.

using the Eclipse treatment planning system (Varian Medical Systems, Palo Alto, CA, USA) with 6 MV photons (Figure 3). SBRT employed a NovalisTx system (Varian Medical Systems and BrainLab, Feldkirchen, Germany). The dose was
55 Gy in five daily fractions, and the treatment was continued for 7 days including a weekend.

The patient was closely followed-up at the outpatient clinic every 1-2 weeks for 2 months and once every

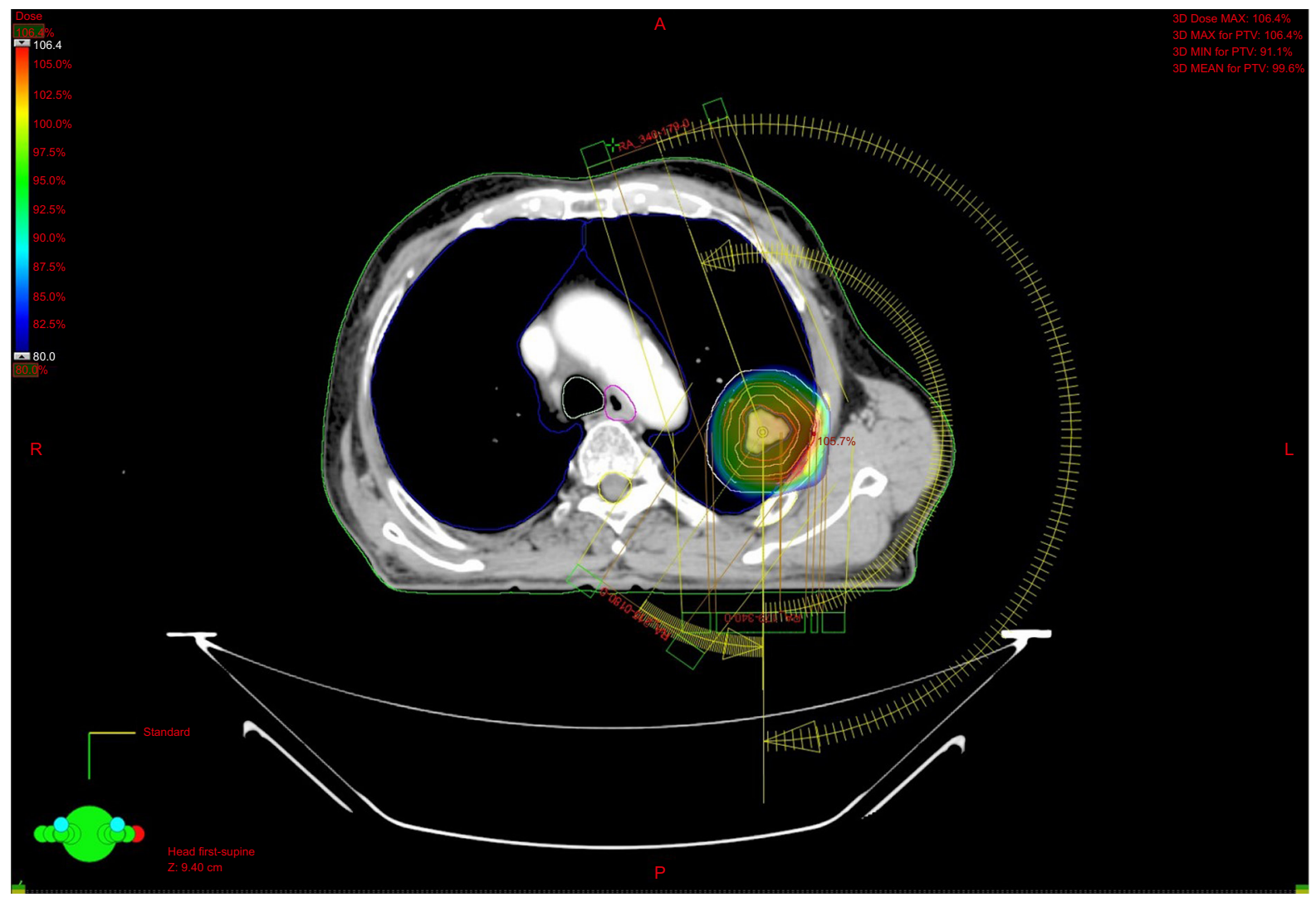

Figure 3 SBRT plan with volumetric modulated arc technique.

Note: Three arcs were used from $340^{\circ}$ to $179^{\circ}$ (clockwise and counterclockwise) and from $215^{\circ}$ to $180^{\circ}$.

Abbreviation: SBRT, stereotactic body radiation therapy. 

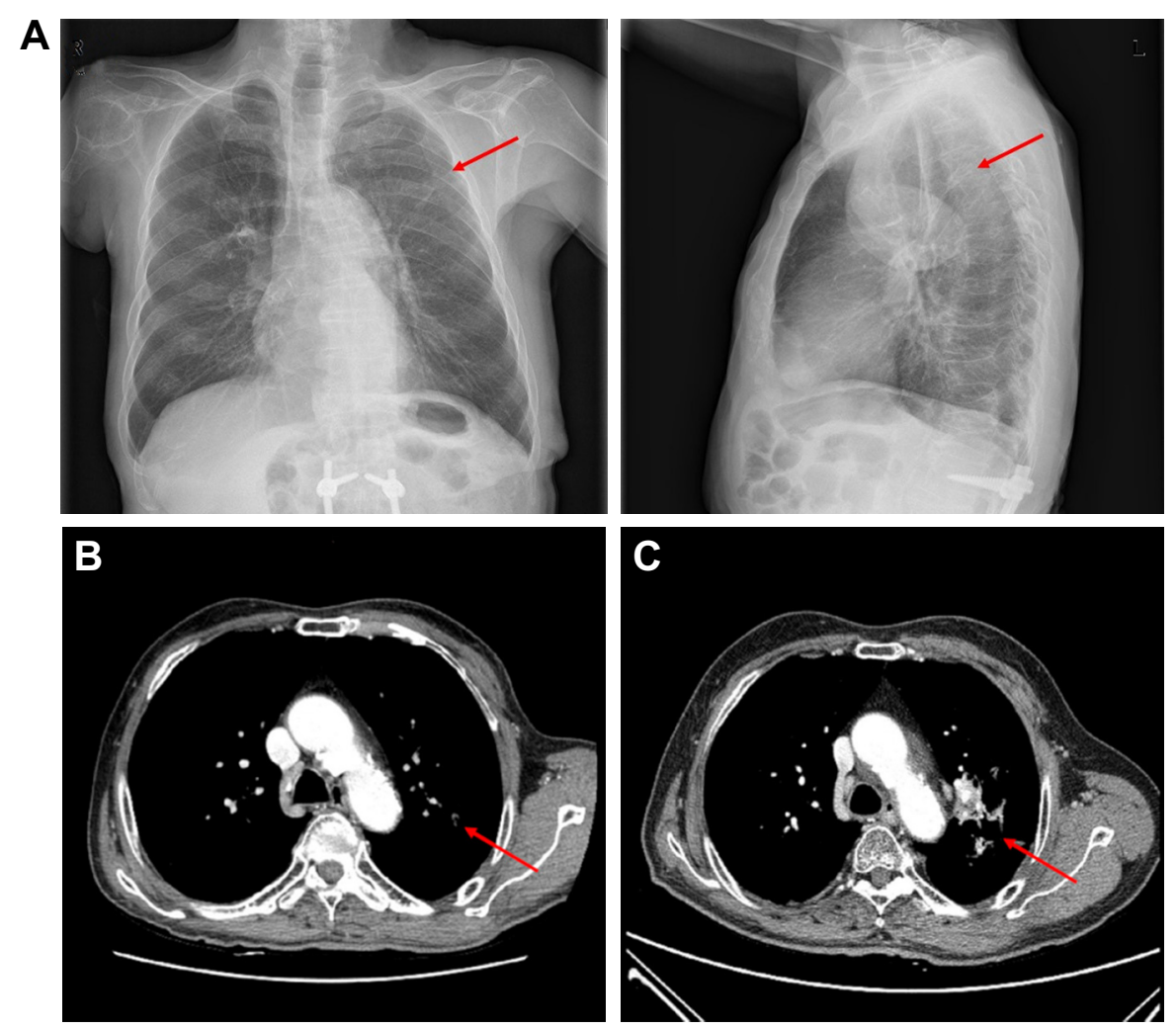

Figure 4 Posttreatment chest images.

Notes: Chest X-ray (A) and CT (B) 2 months after SBRT revealed a greatly regressed small nodule (red arrows). (C) Chest CT performed I year after SBRT evidenced only irregular consolidation around the treated region, indicating a complete tumor response (red arrow) and development of radiation fibrosis.

Abbreviations: CT, computed tomography; SBRT, stereotactic body radiation therapy.

1-3 months thereafter. Follow-up featured physical examination, a complete blood count, a liver function test, and a chest X-ray or CT. A much-reduced small nodule was shown on chest CT 2 months after SBRT. Chest CT 1 year after SBRT demonstrated only irregular consolidation around the treated region, indicating a complete tumor response along with radiation fibrosis (Figure 4). ${ }^{9}$ During the follow-up period, the patient had no other symptoms except an intermittent cough. The patient remains alive with no evidence of disease 18 months after treatment.

\section{Discussion}

LCNEC is very rare and occurs in $\sim 1 \%$ of all lung cancers, which is also the case in Korea. ${ }^{2}$ This tumor is usually found in males, and the median age is 64 years. ${ }^{10}$ Smoking history greatly influences this tumor. Only limited information on the natural history, clinical course, and optimal management of LCNEC patients is available. LCNEC, together with SCLC, was grouped into neuroendocrine neoplasms in the 2015 WHO classification; however, the National Comprehensive Cancer Network recommends treatment according to the NSCLC guidelines. ${ }^{11}$ Some studies have suggested that SCLC-based chemotherapy regimens with platinum and etoposide should be used, while others have shown that an NSCLC-based chemotherapy regimen is better. ${ }^{12-14}$ Surgical resection is recommended for patients with nonmetastatic tumors, reflecting the NSCLC treatment guidelines. ${ }^{4,15}$

Only a small number of patients with LCNEC have received (conventionally fractionated) RT. Among them, some were treated with postoperative RT alone or concurrent chemoradiotherapy (CCRT) with 50-60 Gy, ${ }^{16,17}$ or definitive CCRT with $66-70.5 \mathrm{~Gy},{ }^{16}$ or preoperative RT with 40 Gy. ${ }^{18}$ Rieber et $\mathrm{al}^{16}$ reported the use of postoperative RT in cases of pathologic N2 disease or incomplete resection after surgery, and definitive CCRT was performed at more advanced stages in inoperable patients. Rieber et al ${ }^{16}$ also reported 2- and 5-year overall survival rates of 39\% and $29 \%$, respectively, in stage III-IV LCNEC. In addition, the 2 - and 5-year progression-free survival was $74 \%$ and $38 \%$, respectively, in all stages, indicating that $\mathrm{RT}$ effectively treats LCNEC. Filosso et $\mathrm{al}^{17}$ reported the use of adjuvant RT without chemotherapy in all patients with more advanced stage than IB after surgery. Filosso et $\mathrm{al}^{17}$ also reported 3- and 5 -year overall survival rates of $63 \%$ and $35 \%$, respectively. 
Maeda et al ${ }^{18}$ reported that $66 \%$ of the tumor volume was reduced by using only 40 Gy of CCRT; therefore, preoperative CCRT should be considered a treatment option to facilitate complete resection.

SBRT is characterized by high-level irradiation with a marked difference in the dose gradients to the tumor and normal tissues, and was associated with significantly improved local control and overall survival (compared with conventional RT) in medically inoperable patients with early stage NSCLC. ${ }^{8,19,20}$ In addition, SBRT is safe and convenient even for patients with poor lung function caused by smoking or underlying pulmonary disease. ${ }^{8,21}$ However, SBRT is not yet an established treatment option for early stage SCLC. Only a few experimental case series have used SBRT to this end. ${ }^{8,22}$ In the LCNEC context, a few SBRT studies on early stage NSCLC patients included cases with LCNEC histology, but the treatment outcomes were not separately described..$^{23}$ To the best of our knowledge, our present study is the first to report the outcomes of SBRT in an LCNEC patient.

Our patient refused surgery but requested RT. SBRT featured 55 Gy delivered in five fractions. The patient completed treatment without any adverse effects. The patient has been relapse-free for 18 months post SBRT, although further long-term follow-up is required.

\section{Conclusion}

We report an early stage LCNEC case treated via SBRT. If surgical resection is not possible in early stage LCNEC patients, SBRT could be a favorable treatment method.

\section{Acknowledgment}

This work was supported by the Soonchunhyang University Research Fund.

\section{Disclosure}

The authors report no conflicts of interest in this work.

\section{References}

1. Derks JL, Hendriks LE, Buikhuisen WA, et al. Clinical features of large cell neuroendocrine carcinoma: a population-based overview. Eur Respir J. 2016;47(2):615-624.

2. Shin A, Oh CM, Kim BW, Woo H, Won YJ, Lee JS. Lung cancer epidemiology in Korea. Cancer Res Treat. 2017;49(3):616-626.

3. Iyoda A, Makino T, Koezuka S, Otsuka H, Hata Y. Treatment options for patients with large cell neuroendocrine carcinoma of the lung. Gen Thorac Cardiovasc Surg. 2014;62(6):351-356.

4. Welter S, Aigner C, Roesel C. The role of surgery in high grade neuroendocrine tumours of the lung. J Thorac Dis. 2017;9(Suppl 15): S1474-S1483.
5. Yu XJ, Dai WR, Xu Y. Survival outcome after stereotactic body radiation therapy and surgery for early stage non-small cell lung cancer: a meta-analysis. J Invest Surg. 2017:1-8.

6. Yeo SG, Kim ES. Efficient approach for determining four-dimensional computed tomography-based internal target volume in stereotactic radiotherapy of lung cancer. Radiat Oncol J. 2013;31(4):247-251.

7. Chang JY, Senan S, Paul MA, et al. Stereotactic ablative radiotherapy versus lobectomy for operable stage I non-small-cell lung cancer: a pooled analysis of two randomised trials. Lancet Oncol. 2015;16(6): 630-637.

8. Yeo SG, Kim MJ. Stereotactic body radiation therapy for the treatment of a post-chemotherapy remnant lung mass in extensive-stage small-cell lung cancer: a case report. Exp Ther Med. 2016;12(2):1185-1188.

9. Huang K, Palma DA. IASLC Advanced Radiation Technology Committee. Follow-up of patients after stereotactic radiation for lung cancer: a primer for the nonradiation oncologist. J Thorac Oncol. 2015; 10(3):412-419.

10. Park MS, Kim KD, Chung JH, et al. Clinical features of pulmonary large cell neuroendocrine carcinoma. Cancer Res Treat. 2003;35(3):245-253.

11. Naidoo J, Santos-Zabala ML, Iyriboz T, et al. Large cell neuroendocrine carcinoma of the lung: clinico-pathologic features, treatment, and outcomes. Clin Lung Cancer. 2016;17(5):e121-e129.

12. Sun JM, Ahn MJ, Ahn JS, et al. Chemotherapy for pulmonary large cell neuroendocrine carcinoma: similar to that for small cell lung cancer or non-small cell lung cancer? Lung Cancer. 2012;77(2):365-370.

13. Rossi G, Cavazza A, Marchioni A, et al. Role of chemotherapy and the receptor tyrosine kinases KIT, PDGFRalpha, PDGFRbeta, and Met in large-cell neuroendocrine carcinoma of the lung. J Clin Oncol. 2005; 23(34):8774-8785.

14. Derks JL, van Suylen RJ, Thunnissen E, et al. Chemotherapy for pulmonary large cell neuroendocrine carcinomas: does the regimen matter? Eur Respir J. 2017;49(6):1601838.

15. Kujtan L, Muthukumar V, Kennedy KF, Davis JR, Masood A, Subramanian J. The role of systemic therapy in the management of stage I large cell neuroendocrine carcinoma of the lung. J Thorac Oncol. 2018;13(5):707-714.

16. Rieber J, Schmitt J, Warth A, et al. Outcome and prognostic factors of multimodal therapy for pulmonary large-cell neuroendocrine carcinomas. Eur J Med Res. 2015;20(1):64.

17. Filosso PL, Ruffini E, Oliaro A, et al. Large-cell neuroendocrine carcinoma of the lung: a clinicopathologic study of eighteen cases and the efficacy of adjuvant treatment with octreotide. J Thorac Cardiovasc Surg. 2005;129(4):819-824.

18. Maeda A, Nakata M, Yasuda K, et al. Unknown primary large cell neuroendocrine carcinoma (LCNEC) in the mediastinum. Gen Thorac Cardiovasc Surg. 2013;61(9):542-545.

19. Widder J, Postmus D, Ubbels JF, Wiegman EM, Langendijk JA. Survival and quality of life after stereotactic or 3D-conformal radiotherapy for inoperable early-stage lung cancer. Int J Radiat Oncol Biol Phys. 2011;81(4):e291-e297.

20. Kim K, Lee J, Cho Y, et al. Predictive factors of symptomatic radiation pneumonitis in primary and metastatic lung tumors treated with stereotactic ablative body radiotherapy. Radiat Oncol J. 2017;35(2):163-171.

21. Guckenberger M, Andratschke N, Alheit H, et al. Definition of stereotactic body radiotherapy: principles and practice for the treatment of stage I non-small cell lung cancer. Strahlenther Onkol. 2014;190(1):26-33.

22. Stahl JM, Corso CD, Verma V, et al. Trends in stereotactic body radiation therapy for stage I small cell lung cancer. Lung Cancer. 2017;103: 11-16.

23. Chang JY, Liu YH, Zhu Z, et al. Stereotactic ablative radiotherapy: a potentially curable approach to early stage multiple primary lung cancer. Cancer. 2013;119(18):3402-3410. 


\section{Publish your work in this journal}

OncoTargets and Therapy is an international, peer-reviewed, open access journal focusing on the pathological basis of all cancers, potential targets for therapy and treatment protocols employed to improve the management of cancer patients. The journal also focuses on the impact of management programs and new therapeutic agents and protocols on

patient perspectives such as quality of life, adherence and satisfaction. The manuscript management system is completely online and includes a very quick and fair peer-review system, which is all easy to use. Visit http://www.dovepress.com/testimonials.php to read real quotes from published authors.

Submit your manuscript here: http://www.dovepress.com/oncotargets-and-therapy-journal 